\title{
Strong metal-support interactions between palladium and iron oxide and their effect on CO oxidation
}

Raoul Naumann d'Alnoncourt ${ }^{\mathrm{a}}$, Matthias Friedrich ${ }^{\mathrm{a}}$, Edward Kunkes ${ }^{\mathrm{a}}$, Dirk Rosenthal ${ }^{\mathrm{a}}$, Frank Girgsdies ${ }^{\mathrm{a}}$, Bingsen Zhang, Lidong Shao ${ }^{\mathrm{a}, \mathrm{b}}$, Manfred Schuster ${ }^{\mathrm{a}}$, Malte Behrens ${ }^{\mathrm{a}, \mathrm{c}}$, Robert Schlögl ${ }^{\mathrm{a}}$

a Fritz Haber Institute of the Max Planck Society, Department of Inorganic Chemistry, Faradayweg 4-6, 14195 Berlin, Germany

${ }^{\mathrm{b}}$ College of Environmental and Chemical Engineering, Shanghai University of Electric Power, Shanghai 200090, PR China

${ }^{\mathrm{c}}$ Universität Duisburg-Essen, Fakultät für Chemie, Universitätsstraße 5, 45141 Essen, Germany

corresponding author: Matthias Friedrich, friedrich@fhi-berlin.mpg.de, Fritz Haber Institute of the Max Planck Society, Department of Inorganic Chemistry, Faradayweg 4-6, 14195 Berlin, Germany phone: +4930 / 8413-4611

\begin{abstract}
$\mathrm{Pd} / \mathrm{FeO}_{\mathrm{x}}$ catalysts were prepared by co-precipitation and characterized before and after reduction using X-ray powder diffraction, thermal analysis, $\mathrm{CO}$ chemisorption, electron microscopy, and X-ray photoelectron spectroscopy. Results give evidence for the encapsulation of palladium particles by iron oxide after reduction at high temperatures $(523 \mathrm{~K})$. Oxidation of carbon monoxide was applied as test reaction to characterize catalyst samples in different states. Strong metal-support interactions significantly enhance catalytic activity for oxidation of carbon monoxide. However, this state is not stable under the applied reaction conditions. Catalyst deactivation occurs in two ways: 1 . via changes in the oxidation state of iron species and 2. due to sintering of palladium particles.
\end{abstract}

\section{Introduction}

The term "strong metal-support interactions" (SMSI) was introduced in 1978 by Tauster et al. [1]. The authors reported considerably decreased sorption capacity for $\mathrm{CO}$ and $\mathrm{H}_{2}$ on Group VIII noble metals supported on $\mathrm{TiO}_{2}$ after reduction at $773 \mathrm{~K}$, compared to the state after reduction at $473 \mathrm{~K}$. The effect could be reversed by calcination of the samples at $673 \mathrm{~K}$. No indication for 
agglomeration or sintering of the metal particles was found. The authors concluded that the observed effect was initiated by metal-metal bonding between noble metal and titanium cations or by to the formation of intermetallic compounds. Further studies proved that the effect was not restricted to $\mathrm{TiO}_{2}$. In 1981, Tauster et al. showed that the occurrence of SMSI correlates with the reducibility of transition metal oxides used as support [2]. The effect was observed for Ir supported on $\mathrm{Nb}_{2} \mathrm{O}_{5}, \mathrm{TiO}_{2}, \mathrm{Ta}_{2} \mathrm{O}_{5}, \mathrm{~V}_{2} \mathrm{O}_{3}$ or $\mathrm{MnO}$, but not for Ir on $\mathrm{ZrO}_{2}, \mathrm{HfO}_{2}, \mathrm{Y}_{2} \mathrm{O}_{3}$ or $\mathrm{Sc}_{2} \mathrm{O}_{3}$. It was concluded that the loss of sorption capacity is caused by support species migrating onto the noble metal particles, thus reducing the accessible surface of the metal crystallites by encapsulation, rather than electronic effects induced by metal-metal bonding [3-6]. In 1989, Braunschweig et al. confirmed the encapsulation model for $\mathrm{Rh}$ on $\mathrm{TiO}_{2}$ by transmission electron microscopy (TEM) [7]. In another TEM study, Datye et al. visualized the encapsulation of Pt by $\mathrm{TiO}_{2}$ in the SMSI state [8].

The effects of SMSI states on catalytic properties are summarized in a review by Uchijima, focusing on $\mathrm{Rh}$ and $\mathrm{Pd}$ supported on $\mathrm{Nb}_{2} \mathrm{O}_{5}$ as model catalysts [9]. In general, structure-sensitive reactions such as hydrogenolysis of hydrocarbons or hydrogenation of $\mathrm{CO}$ are strongly suppressed in the SMSI state. This effect is usually rationalized by geometric ensemble effects. In contrast, structure-insensitive reactions, e.g. dehydrogenation/hydrogenation of hydrocarbons, are only mildly suppressed. During $\mathrm{CO}$ hydrogenation by $\mathrm{Rh} / \mathrm{Nb}_{2} \mathrm{O}_{5} / \mathrm{SiO}_{2}$ catalysts, $\mathrm{Nb}_{2} \mathrm{O}_{5}$ acts as promoter after reduction at low temperature, but suppresses activity in the SMSI state via the ensemble effect. The hydroformylation of ethylene is catalyzed by $\mathrm{Pd} / \mathrm{Nb}_{2} \mathrm{O}_{5}$ in the SMSI state, but not by $\mathrm{Pd} / \mathrm{Nb}_{2} \mathrm{O}_{5}$ in the state after reduction at low temperature. Presumably, $\mathrm{NbO}_{\mathrm{x}}$ species on the Pd surface act as ligand for $\mathrm{CO}$, thus creating new reaction sites.

Freund and coworkers investigated the $\mathrm{Pt} / \mathrm{Fe}_{3} \mathrm{O}_{4}(111) / \mathrm{Pt}(111)$ model system in UHV studies [1013]. They reported the existence of SMSI between $\mathrm{Pt}$ and $\mathrm{Fe}_{3} \mathrm{O}_{4}$. Upon annealing above $800 \mathrm{~K}$, iron oxide species formed a monolayer on the surface, thereby fully encapsulated the Pt particles resulting in reduced $\mathrm{CO}$ adsorption capacity but increased $\mathrm{CO}$ oxidation activity. Indications for SMSI were also found for the systems $\mathrm{ZnO}(0001) / \mathrm{Pt}(111), \quad \mathrm{MnO} / \mathrm{Pt}(111)$ and $\mathrm{Pd} / \mathrm{FeO}(111) / \operatorname{Pt}(111)$ [14-16].

$\mathrm{CO}$ oxidation can serve as a model reaction for more complex heterogeneous reactions [17]. It has been studied extensively using Pd as catalyst. The activity in CO oxidation on Pd on different supports is known to be influenced by the reducibility of the support [18]. The studies range 
from probing single crystal surfaces as well as supported catalysts. Pd supported on iron oxide is investigated in several papers [19-26]. It was found that Pd supported on iron oxide is highly active in $\mathrm{CO}$ oxidation, at temperatures unusually low even for Pd. Independent from the pressure range, it is suggested that the reaction follows a Langmuir-Hinshelwood mechanism on Pt group metals ( $\mathrm{Pd}, \mathrm{Pt}, \mathrm{Rh}$ ) [27-29]. $\mathrm{CO}$ is adsorbed on the metal, $\mathrm{O}_{2}$ is adsorbed on the support, and the reaction takes place at the metal/support perimeter. The high activity of $\mathrm{Pd}$ on iron oxide at low temperature is mainly attributed to the redox properties and oxygen storage capabilities of iron oxides. Partially reduced iron oxide (i.e. $\mathrm{Fe}_{3} \mathrm{O}_{4}$ ) provides sorption sites for $\mathrm{O}_{2}$ in form of $\mathrm{Fe}^{2+}$ ions and thereby acts as oxygen sink.

Pd supported on different iron oxides has been reported to show great potential as catalyst in other reactions, i.e. aqueous-phase reforming of ethylene glycol [30], selective dechlorination [31] and denitrification of water [32].

In the present study, well characterized catalyst samples of Pd supported on various iron oxides are investigated aiming at a deeper understanding of the nature of the interaction between $\mathrm{Pd}$ and iron oxide. The oxidation of $\mathrm{CO}$ is applied as test reaction to characterize samples in different states. Parts of this study have already been included in a previous publication [17].

\section{Experimental}

\subsection{Preparation}

$\mathrm{PdO} / \alpha-\mathrm{Fe}_{2} \mathrm{O}_{3}$ was synthesized by co-precipitation in an automated laboratory reactor system (Labmax, Mettler Toledo). A 0.2 M metal salt solution was prepared by dissolving $\mathrm{Fe}\left(\mathrm{NO}_{3}\right)_{3} \cdot 9 \mathrm{H}_{2} \mathrm{O}$ (Aldrich) and $\mathrm{Pd}\left(\mathrm{NO}_{3}\right)_{2}$ solution in $10 \mathrm{wt}$. \% $\mathrm{HNO}_{3}$ (Alfa Aesar) in deionized water to yield a final Pd content of $2 \mathrm{wt}$ \% on the support. Precipitation was performed at $298 \mathrm{~K}$ by simultaneously controlled drop-wise addition of the metal solution $(450 \mathrm{~mL}, 10 \mathrm{~mL} / \mathrm{min})$ and a $0.6 \mathrm{M} \mathrm{NaOH}$ solution into $400 \mathrm{~mL}$ deionized water. The $\mathrm{pH}$ was maintained at 9 during the precipitation. The precipitate was aged for $1 \mathrm{~h}$ and subsequently washed with 3 batches $(1 \mathrm{~L})$ of deionized water. Electric conductivity of the filtrate after the third washing step was below $0.02 \mathrm{mS}$. The washed precipitate was dried at $298 \mathrm{~K}$ under flowing air for $12 \mathrm{~h}$ and subsequently calcined in air at $823 \mathrm{~K}$ for $2 \mathrm{~h}(2 \mathrm{~K} / \mathrm{min})$ to yield $\mathrm{PdO} / \alpha-\mathrm{Fe}_{2} \mathrm{O}_{3}$.

Pure hematite $\left(\alpha-\mathrm{Fe}_{2} \mathrm{O}_{3}\right)$ and $\mathrm{Pd} / \mathrm{CNT}$ (cf. SI) were synthesized for comparison. $\alpha-\mathrm{Fe}_{2} \mathrm{O}_{3}$ was prepared in the same way as $\mathrm{Pd} / \alpha-\mathrm{Fe}_{2} \mathrm{O}_{3}$, excluding $\mathrm{Pd}$ in the metal nitrate solution. 


\subsection{Characterization}

Thermogravimetry coupled with differential scanning calorimetry (TG-DSC) was carried out in a thermobalance (Netzsch STA 449C Jupiter) connected to a mass spectrometer (Omnistar, Pfeiffer) and equipped with a gas mixing unit. To determine a suitable temperature for calcination, precursor samples were heated in a stream of pure $\operatorname{Ar}(100 \mathrm{~mL} / \mathrm{min})$ from room temperature to $1273 \mathrm{~K}$ with a heating rate of $10 \mathrm{~K} / \mathrm{min}$. The reduction behavior of iron oxides was investigated by heating calcined samples in a stream of $5 \% \mathrm{H}_{2}$ in $\mathrm{Ar}(100 \mathrm{~mL} / \mathrm{min})$ from room temperature to $973 \mathrm{~K}$ with a heating rate of $5 \mathrm{~K} / \mathrm{min}$.

X-ray diffraction (XRD) was performed in Bragg-Brentano reflection geometry on a theta/theta diffractometer (D8 Advance, Bruker AXS) equipped with a secondary graphite monochromator $\left(\mathrm{Cu} \mathrm{K \alpha} \alpha_{1+2}\right.$ radiation) and scintillation detector. Larger amounts of sample powder, if available, were filled into a cup-shaped sample holder, the surface of the powder bed being flush with the sample holder edge. Alternatively, smaller amounts of sample were dispersed onto the surface of a low-background single-crystal silicon sample holder. XRD data in reactive atmospheres were collected in Bragg-Brentano reflection geometry on a STOE theta/theta X-ray diffractometer $\left(\mathrm{Cu} \mathrm{K} \alpha_{1+2}\right.$ radiation, secondary graphite monochromator, scintillation counter) equipped with an in situ reactor chamber (XRK 900, Anton Paar). The reaction gas feed was mixed by mass flow controllers (Bronkhorst) using He as inert balance gas at a total flow rate of $100-150 \mathrm{~mL} / \mathrm{min}$. The effluent product gas composition was monitored by a quadrupole mass spectrometer (Omnistar, Pfeiffer). Calcined samples were investigated in the initial state, after reduction in 5\% $\mathrm{H}_{2}$ at $523 \mathrm{~K}(100 \mathrm{~mL} / \mathrm{min})$, after $\mathrm{CO}$ oxidation reaction in gas mixtures $(150 \mathrm{~mL} / \mathrm{min})$ of $4.0 \%$ $\mathrm{CO} / 0.5 \% \mathrm{O}_{2}$ and of $1.0 \% \mathrm{CO} / 0.5 \% \mathrm{O}_{2}$ at $523 \mathrm{~K}$, and finally after calcination at $673 \mathrm{~K}$ and $1073 \mathrm{~K}$ in $20 \% \mathrm{O}_{2}(100 \mathrm{~mL} / \mathrm{min})$. All diffraction patterns were recorded at room temperature. Data analysis was performed using the software package Topas (v 2.1, Bruker AXS). Crystallite size values are based on the double-Voigt approach and reported as $\mathrm{L}_{\mathrm{Vol}}-\mathrm{IB}$ values (volume weighted mean column length based on integral breadth) without further assumptions about crystallite shape or size distribution [33]. Some samples exhibited a certain degree of anisotropic peak broadening, i.e. the diffraction profile is not only a function of the diffraction angle $2 \theta$ but also of the direction in the crystallites and thus hkl. Such anisotropic peak broadening can be rationalized by shape anisotropy of the crystallites. Nevertheless, the data was fitted with the isotropic double-Voigt model for more convenient parameterization of the fit results. 
BET measurements were carried out in a volumetric $\mathrm{N}_{2}$ physisorption set-up (Autosorb-6-B, Quantachrome) at the temperature of liquid nitrogen. Samples were degassed in dynamic vacuum at $423 \mathrm{~K}$ for $2 \mathrm{~h}$ prior to physisorption. Full adsorption and desorption isotherms were measured. In general, 11 points in the linear range of the desorption isotherm were considered to calculate the specific surface area according to the BET method [34].

$\mathrm{CO}$ chemisorption was carried out at $313 \mathrm{~K}$ in a volumetric chemisorption set-up equipped for sample pretreatment in flowing gas (Autosorb-1-C, Quantachrome). Samples ( $\mathrm{PdO} / \gamma-\mathrm{Fe}_{2} \mathrm{O}_{3}: 300$ $\mathrm{mg}, \mathrm{Pd} / \mathrm{CNT}$ : $180 \mathrm{mg}$ ) were degassed in dynamic vacuum at the end temperature of the pretreatment (reduction: RT, $423 \mathrm{~K}$ or $523 \mathrm{~K}$, oxidation: $673 \mathrm{~K}$ ) for $60-90 \mathrm{~min}$ prior to chemisorption experiments. Two adsorption isotherms were measured at $313 \mathrm{~K}$ in the pressure range of 3-747 $\mathrm{hPa}$, the first isotherm corresponding to both weakly and strongly adsorbed species and the second isotherm corresponding only to weakly adsorbed species. The difference of both isotherms represents the amount of strongly adsorbed species. Since carbonate formation on iron oxides cannot be excluded, the calculated dispersion values might be overestimated. Nevertheless, comparison of relative changes of the dispersion of one sample after different treatments is valid.

Electron microscopy and energy dispersive X-ray spectroscopy (EDX) were applied to investigate samples in the state after calcination, after reduction or after $\mathrm{CO}$ oxidation. The respective treatments were carried out in the set-up used for catalytic tests (see below). Samples were transferred into the microscope via a glove box $\left(\mathrm{O}_{2}\right.$ and $\mathrm{H}_{2} \mathrm{O}$ concentration below $\left.1 \mathrm{ppm}\right)$ without contact to air. A Philips CM 200 FEG TEM operated at $200 \mathrm{kV}$ and a Hitachi S-4800 SEM were used to study the morphology and microstructure of samples. A FEI Cs-corrected Titan 80-300 microscope was employed to acquire STEM and HR-TEM images. An energy dispersive X-ray detector (Genesis 4000) attached to the FEG TEM was used to conduct elemental mapping and composition analysis.

In situ X-ray photoelectron spectroscopy (XPS) was performed at ISISS beamline at BESSY II synchrotron facility at the Helmholtz Zentrum Berlin, in a setup described elsewhere [35]. The samples were mounted on a sapphire sample holder, which could be heated from the rear by an IR laser (continuous wave, $808 \mathrm{~nm}$ ). The temperature was measured by a K-type thermocouple fixed onto the sample surface. The gas flow into the analysis chamber was controlled by mass flow controllers (Bronkhorst). Sample treatments and XPS measurements were performed 
simultaneously in $25 \mathrm{~Pa}$ of $\mathrm{He}, \mathrm{H}_{2}$, or $\mathrm{O}_{2}$. A differentially pumped quadrupole mass spectrometer (Prisma, Pfeiffer) was connected through a leak valve to the experimental cell to monitor the gas phase composition. The photoelectron spectra were normalized by the storage ring current and the energy dependent incident photon flux, which was measured prior to the measurements using a gold foil with known quantum efficiency. The photon flux obtained has been corrected for higher diffraction orders that contribute only to the background but not to the peak intensity in XPS. The binding energy scale was calibrated with respect to the Fermi level of the electron analyzer. The XPS spectra were recorded at a constant electron kinetic energy of $150 \mathrm{eV}$ by varying the excitation energy for each core orbital measured. The corresponding inelastic mean free path (IMFP) is about $0.6 \mathrm{~nm}$, as calculated for pure $\mathrm{Fe}_{2} \mathrm{O}_{3}$ using the NIST Standard Reference Database [36, 37]. Semi-quantitative calculations were performed using normalized Fe $2 \mathrm{p}$ and $\mathrm{Pd} 3 \mathrm{~d}$ intensities, taking into account the photon-energy dependence of the atomic subshell photo-ionization cross sections [38]. Peak positions were referenced to the O 1s peak following ref. [39, 40].

\subsection{Catalytic testing}

The oxidation of $\mathrm{CO}$ was investigated as catalytic test reaction in a plug-flow reactor. The measurements were carried out in a set-up consisting of a gas dosing section, a reactor inside a copper block oven, and two on-line gas analyzer units. The gas dosing section includes lines for $\mathrm{Ar}, \mathrm{He}, \mathrm{H}_{2}, \mathrm{O}_{2}$, and three calibration gases $\left(5 \% \mathrm{H}_{2}\right.$ in $\mathrm{Ar}, 5 \% \mathrm{O}_{2}$ in $\mathrm{He}$, and $5 \% \mathrm{CO}$ in $\left.\mathrm{Ar}\right)$. Each line consists of a filter, a mass flow controller (El-Flow, Bronkhorst), a check valve, and a shutoff valve. The gases can be mixed via custom-designed switching valves (Valco, Vici). The reactor itself is a U-tube reactor with an outer diameter of $0.25^{\prime \prime}$ made of glass lined steel (Glass Lined Tubing, SGE). It is connected to a four-way valve (Valco, Vici) used as bypass and for sealing the reactor during sample transfer into the glove box. The reactor is heated by a custommade copper block oven, providing an isothermal $( \pm 1 \mathrm{~K})$ zone of $10 \mathrm{~cm}$ at temperatures up to $673 \mathrm{~K}$. The sample temperature is monitored by an internal thermocouple of type K. Analytics are performed by an on-line detector consisting of two IR detectors for $\mathrm{CO}$ and $\mathrm{CO}_{2}$ (EL 1020, ABB) and a second on-line detector including a thermal conductivity detector for $\mathrm{H}_{2}$ and a paramagnetic sensor for $\mathrm{O}_{2}$ (X-Stream, Rosemount).

In a typical experiment ca. $25 \mathrm{mg}$ of sample (sieve fraction $255-350 \mu \mathrm{m}$ ) were diluted by 250 $\mathrm{mg} \mathrm{SiC}$ of the same sieve fraction. The resulting catalyst bed was ca. $2 \mathrm{~cm}$ in length and ca. 2 
$\mathrm{cm}^{3}$ in volume. Pre-reduction of the catalysts was either done at room temperature or at $523 \mathrm{~K}$ (2 $\mathrm{K} / \mathrm{min}$, holding for $30 \mathrm{~min}$ ), both in $5 \% \mathrm{H}_{2}$ in Ar at a total gas flow of $80 \mathrm{ml} / \mathrm{min}$. CO oxidation was investigated in the temperature range from room temperature to $523 \mathrm{~K}$. The feed consisted of $1.0 \% \mathrm{CO}$ and $0.5 \% \mathrm{O}_{2}$ balanced with a mixture of $\mathrm{He}$ and Ar. The total flow was set to $100 \mathrm{~mL} / \mathrm{min}$, giving a gas hourly space velocity of $240,000 \mathrm{~mL} \mathrm{~g}^{-1} \mathrm{~h}^{-1}$. The deactivation behavior of the samples was tested by temperature cycles ( 5 repetitions) in the range of 350-523 $\mathrm{K}$ with a rate of $1 \mathrm{~K} / \mathrm{min}$ and holding times of $30 \mathrm{~min}$ at $523 \mathrm{~K}$. After deactivation, reaction rates were measured for $0.5-4 \mathrm{~h}$ at constant temperatures chosen to yield conversions below $25 \%$. The conversion of CO in the empty reactor was below 0.005 at $523 \mathrm{~K}$. Significant conversion of CO started at $573 \mathrm{~K}$ and reached 0.1 at $635 \mathrm{~K}$, which is above the investigated temperature range.

\section{Results and discussion}

\subsection{Characterization of calcined samples}

After investigating the Pd-containing and Pd-free precipitates by TG-DSC in Ar, a calcination temperature of $823 \mathrm{~K}$ was derived for both samples to enable complete precursor decomposition and crystallization of the iron oxide phase (see supporting information, Fig. S1 and Table S1). XRD patterns of the calcined samples and of the Pd-containing sample after calcination at a lower temperature (673 K), i.e. before the exothermic process (cf. Fig. S1), are included in Fig. 1, corresponding crystallographic data is given in Table S2. All sharp reflections in the pattern of the samples calcined at $823 \mathrm{~K}$ (Fig. $1 \mathrm{a}+\mathrm{c})$ can be assigned to hematite $\left(\alpha-\mathrm{Fe}_{2} \mathrm{O}_{3}\right)$. Rietveld fit confirms the presence of palladium oxide as minority phase in $\mathrm{PdO} / \alpha-\mathrm{Fe}_{2} \mathrm{O}_{3}$ and indicates possible shape anisotropy of the hematite crystallites in both samples (Fig. S2).

The XRD pattern of the Pd-containing sample after calcination at $673 \mathrm{~K}$ (Fig. 1 b) shows a series of reflections that are solely assigned to hematite. Some very broad reflections may be a contribution of amorphous or nanocrystalline material, which would be in line with the DSC profile (Fig. S1). Rietveld fit of the profile using two patterns of hematite with different crystallite sizes gives a good approximation of the experimental profile.

SEM micrographs of the calcined samples confirm the results obtained by XRD and TG-DSC (Fig. 2). After calcination at $823 \mathrm{~K}$ uniformly elongated particles with widths and lengths in the range of 10 and $100 \mathrm{~nm}$, respectively, can be seen (Fig. 2 b). After calcination at $673 \mathrm{~K}$ much 
smaller particles, almost not distinguishable using SEM, are observed (Fig. 2 a). EDX analysis of the Pd containing samples gave local palladium contents of 2.0-2.1 wt. \%, which is in excellent agreement with the nominal content and confirms the homogeneous distribution of $\mathrm{Pd}$.

The data from $\mathrm{N}_{2}$ physisorption experiments shown in Fig. S3 are in qualitative agreement with the results obtained by TG-DSC, XRD and SEM. The adsorption isotherms of the Pd-free and the Pd-containing sample after calcination at $823 \mathrm{~K}$ are both of type IV with a hysteresis of type H1, typical for agglomerates of compact particles [31]. The fact that the BET surface area of the Pd-free sample is slightly smaller than that of $\mathrm{PdO} / \alpha-\mathrm{Fe}_{2} \mathrm{O}_{3}$ is in accordance with the higher $\mathrm{L}_{\mathrm{vol}}-$ IB value of the $\alpha-\mathrm{Fe}_{2} \mathrm{O}_{3}$ phase derived from XRD, which is a measure for the crystallite size. The $\mathrm{N}_{2}$ adsorption isotherm of the Pd-containing sample after calcination at $673 \mathrm{~K}$ is of type IV with a hysteresis of type H2, typical for porous materials with ill-defined pore structure [31].

\subsection{Characterization of reduced samples}

The calcined samples were reduced in TG-DSC experiments to determine a temperature suitable for reduction of hematite to magnetite $\left(\mathrm{Fe}_{3} \mathrm{O}_{4}\right)$. TG and DSC profiles are shown in Fig. S4, details are given in Table $\mathrm{S} 1$. The data measured on pure $\alpha-\mathrm{Fe}_{2} \mathrm{O}_{3}$ reveals three processes: 1) small mass loss of $0.4 \%$ at temperatures below $523 \mathrm{~K}$ that may be attributed to drying, 2) the reduction from hematite to magnetite in the temperature range of $523-623 \mathrm{~K}$, indicated by a broad and weak exothermic peak in the DSC curve and the mass loss of $3.4 \%$ which is in very good agreement with a theoretical value of $3.3 \%, 3$ ) the beginning reduction of magnetite to iron at temperatures above $623 \mathrm{~K}$. Heating to $973 \mathrm{~K}$ revealed a mass loss of $28.1 \%$, indicating almost complete reduction to iron (theoretical mass loss: 30.1\%). The data obtained on $\mathrm{PdO} / \alpha-\mathrm{Fe}_{2} \mathrm{O}_{3}$ also shows three processes: 1) a mass loss of $1.1 \%$ below $473 \mathrm{~K}$, which may be attributed to drying and possibly to the beginning reduction of hematite, 2) the reduction of hematite to magnetite between $473 \mathrm{~K}$ and $523 \mathrm{~K}$ with a mass loss of $3.1 \%$, giving a sharp peak in the DSC profile, 3 ) the almost complete reduction of iron oxide to iron, with a total mass loss of $26.8 \%$ at $973 \mathrm{~K}$. The reduction of PdO to Pd is not observed in the DSC curve, because it occurred already at room temperature while flushing the DSC apparatus with hydrogen. The fact that in presence of palladium hematite is reduced in a more defined step at lower temperatures, compared to pure $\alpha-\mathrm{Fe}_{2} \mathrm{O}_{3}$, can be explained by spill-over of $\mathrm{H}_{2}$ dissociatively adsorbed on palladium. Based on these results, a reduction temperature of $523 \mathrm{~K}$ was chosen for Pd containing catalysts. Although the total mass loss at $523 \mathrm{~K}$ of $4.2 \%$ indicates that the iron oxide support is not completely in the 
state of magnetite and that some $\mathrm{FeO}$ could be present, reduction at this temperature should yield reproducible states.

XRD patterns of $\mathrm{PdO} / \alpha-\mathrm{Fe}_{2} \mathrm{O}_{3}$ reduced at $523 \mathrm{~K}$ and of $\mathrm{Pd} / \mathrm{Fe}_{3} \mathrm{O}_{4}$ calcined at $673 \mathrm{~K}$ are included in Fig. 1, corresponding crystallographic data is given in Table S2. All major reflections in the pattern of $\mathrm{PdO} / \alpha-\mathrm{Fe}_{2} \mathrm{O}_{3}$ after reduction at $523 \mathrm{~K}$ can be assigned to magnetite (Fig. $1 \mathrm{~d}$ ). Rietveld fit indicates the presence of palladium, palladium oxide and iron as minority phases (Fig. S5). There is no indication in the Rietveld fit for any shape anisotropy of the magnetite crystallites. The profile of $\mathrm{Pd} / \mathrm{Fe}_{3} \mathrm{O}_{4}$ calcined at $673 \mathrm{~K}$ shows reflections that can only be assigned to maghemite $\left(\gamma-\mathrm{Fe}_{2} \mathrm{O}_{3}\right.$, Fig. 1 e). There exist two structural models for maghemite: a simpler cubic model and a more complex tetragonal structure built up of three cubic unit cells [41, 42]. Satisfactory fitting of the profile requires the use of the tetragonal model. No minority phases are needed for the fitting. There is no indication in the Rietveld fit for any shape anisotropy of the maghemite crystallites. No significant change of crystallite sizes due to reduction and subsequent calcination has occurred, considering the $\mathrm{L}_{\mathrm{Vol}}-\mathrm{IB}$ values for $\mathrm{PdO} / \alpha-\mathrm{Fe}_{2} \mathrm{O}_{3}$ reduced at $523 \mathrm{~K}$ and of $\mathrm{Pd} / \mathrm{Fe}_{3} \mathrm{O}_{4}$ calcined at $673 \mathrm{~K}$ in comparison to the Pd-containing precursor material after calcination at $823 \mathrm{~K}$ (Table S2).

This is also reflected by the $\mathrm{N}_{2}$ physisorption data included in Fig. S3. There is no change in the shape of the adsorption isotherms compared to the Pd-containing precursor material after calcination at $823 \mathrm{~K}$. The only difference is an increase in BET surface area in case of $\mathrm{PdO} / \gamma$ $\mathrm{Fe}_{2} \mathrm{O}_{3}$ (Fig. S3 d).

To investigate the size and the distribution of palladium particles, HR-TEM and STEM in HAADF (high-angle annular dark field) mode were applied on $\mathrm{PdO} / \alpha-\mathrm{Fe}_{2} \mathrm{O}_{3}$ after reduction at $523 \mathrm{~K}$ and transfer into the microscopes without contact to air (Fig. 3). The results show that two different types of Pd particles exist in the sample. By HR-TEM only very few and relatively large Pd particles in the range of 5-10 nm were found (Fig. 3 a). In contrast, HAADF STEM experiments revealed the presence of numerous small Pd particles with a mean diameter of $1.0 \pm 0.5 \mathrm{~nm}$, visible as white dots (Fig. 3 b). Elemental mapping of $\mathrm{Pd}, \mathrm{Fe}$, and $\mathrm{O}$ showed that, with the exception of the few larger particles, $\mathrm{Pd}$ is homogeneously distributed on the iron oxide, and EDX confirmed the nominal Pd content of the sample.

In summary, co-precipitation was successfully applied to yield precursor materials for Pdcontaining catalysts supported on different iron oxides. The type of iron oxide could be set by 
applying different thermal treatments, carefully chosen based on TG-DSC data: hematite, magnetite, and maghemite are accessible without other iron oxide phases present (Fig. 4). In all cases, well defined and homogeneous catalysts with large specific surface areas and a high dispersion of Pd were accessible. The crystallite size of iron oxide particles was in the range of $20 \mathrm{~nm}$, while the vast majority of Pd particles had crystallite sizes in the range of 1-2 nm. A reference Pd catalyst supported on SMSI-inert CNT with comparable Pd particle size was synthesized by impregnation of CNT (cf. supp. information).

\subsection{Strong-metal support interaction between Pd and iron oxide}

Strong-metal support interactions are observed when the catalyst support is in a partially reduced state, at least in close vicinity to the noble metal particles. One systematic approach to follow the formation of this state starts from an initially oxidized sample that is subjected to reductive treatments and monitored by different methods. Hence, $\mathrm{PdO} / \gamma-\mathrm{Fe}_{2} \mathrm{O}_{3}$ was chosen to investigate SMSI between palladium and iron oxide, i.e. the reversible encapsulation of Pd particles by iron oxide under reducing conditions. $\mathrm{CO}$ chemisorption was measured after different reduction treatments of $\mathrm{PdO} / \gamma-\mathrm{Fe}_{2} \mathrm{O}_{3}$ to follow the development of surface area and particle sizes. HRTEM was applied to visualize the state of $\mathrm{Pd}$ particles after reduction of $\mathrm{PdO} / \gamma-\mathrm{Fe}_{2} \mathrm{O}_{3}$ at $523 \mathrm{~K}$. Finally, in situ XPS was carried out to probe the surface composition of $\mathrm{PdO} / \gamma-\mathrm{Fe}_{2} \mathrm{O}_{3}$ after reductive and oxidative treatments.

$\mathrm{CO}$ chemisorption experiments consisted of measuring the adsorption isotherm of $\mathrm{CO}$ twice, with evacuation in dynamic vacuum in-between. Both adsorption isotherms and their difference, which represents the amount of strongly adsorbed $\mathrm{CO}$, are shown in Fig. 5, details are given in Table S3. Fig. 5 a) shows the results after reduction of $\mathrm{PdO} / \gamma-\mathrm{Fe}_{2} \mathrm{O}_{3}$ at room temperature, representing a state of completely reduced $\mathrm{Pd}$ while the support is in the oxidized form as $\mathrm{Pd} / \gamma$ $\mathrm{Fe}_{2} \mathrm{O}_{3}$. In this state the dispersion of $\mathrm{Pd}$ is very high at a value of $28 \%$, yielding a free $\mathrm{Pd}$ surface area of $2.54 \mathrm{~m}^{2} / \mathrm{g}_{\text {cat. }}$. Assuming spherical and fully accessible particles a mean diameter of $3.9 \mathrm{~nm}$ can be derived for Pd particles, a value that is in reasonable agreement with the mean particle size of $\mathrm{Pd}$ particles derived from STEM micrographs of $\mathrm{PdO} / \alpha-\mathrm{Fe}_{2} \mathrm{O}_{3}$ after reduction at $523 \mathrm{~K}$. Upon reduction of the sample at $523 \mathrm{~K}$, a state in which the iron oxide support is in its partially reduced form of $\mathrm{Fe}_{3} \mathrm{O}_{4}$, more than $90 \%$ of the free $\mathrm{Pd}$ surface area is lost and dispersion goes down to $2 \%$ (Fig. 5 b). If this loss was due to sintering and particle growth, the resulting particles should have a mean diameter of about $47 \mathrm{~nm}$. Nevertheless, only a few particles in the scale of 
$50 \mathrm{~nm}$ were found by HR-TEM, after transfer into the microscope without contact to air (Fig. 6). Few Pd particles in the range of $5 \mathrm{~nm}$ and many particles in the range of $1 \mathrm{~nm}$ were observed, which is similar to the results obtained for $\mathrm{PdO} / \alpha-\mathrm{Fe}_{2} \mathrm{O}_{3}$ after reduction at $523 \mathrm{~K}$ (Fig. $3 \mathrm{a}+\mathrm{b}$ ). Looking at the Pd particles located at the edge of the iron oxide particles, an amorphous overlayer can be seen that consists of iron oxide, depicting what could possibly be the SMSI state. Since beam irradiation for several minutes has not shown significant changes to the particles and overlayers, carbon accumulation on the particles can be excluded (Fig. S7).

Fig. 5 c) shows the adsorption isotherms measured after re-oxidation of $\mathrm{Pd} / \mathrm{Fe}_{3} \mathrm{O}_{4}$ at $673 \mathrm{~K}$ followed by room temperature reduction. It can be clearly seen, that the changes induced by reduction at $523 \mathrm{~K}$ are almost completely reversible. The dispersion is again above $20 \%$, and the derived mean particle size is $5.3 \mathrm{~nm}$. The change from $3.9 \mathrm{~nm}$ to $5.3 \mathrm{~nm}$ may be related to sintering.

$\mathrm{CO}$ chemisorption experiments investigating the reference sample $\mathrm{PdO} / \mathrm{CNT}$ after reduction at $423 \mathrm{~K}$ and $523 \mathrm{~K}$ showed a similar degree of sintering of Pd particles (see Fig. S8 and Table S3), but not the huge loss of free Pd surface area observed for $\mathrm{Pd} / \gamma-\mathrm{Fe}_{2} \mathrm{O}_{3}$, which can be explained by the non-reducible CNT support that is not capable of encapsulating the Pd particles.

To clarify if the overlayer on Pd particles seen in Fig. 6 is iron oxide, in situ XPS measurements were performed under reducing and oxidizing conditions (Fig. 7 and Table S4). The initial state of $\mathrm{PdO} / \gamma-\mathrm{Fe}_{2} \mathrm{O}_{3}$ was measured at a pressure of $25 \mathrm{~Pa} \mathrm{He}$ at $423 \mathrm{~K}$. The $\mathrm{Pd} 3 \mathrm{~d}_{5 / 2}$ peak is located at $335.5 \mathrm{eV}$ with a resolved shoulder at $337.2 \mathrm{eV}$, indicating the presence of metallic and oxidized palladium, respectively [43]. The position of the Fe $2 p$ doublet $\left(\mathrm{Fe} 2 \mathrm{p}_{3 / 2}\right.$ at $\left.710.8 \mathrm{eV}\right)$ and the satellite in between the $2 p_{1 / 2}$ and $2 p_{3 / 2}$ peaks at $719.0 \mathrm{eV}$ indicate the presence of $\mathrm{Fe}^{3+}$, metallic $\mathrm{Fe}$ is absent [39]. The shoulder on the low BE side of the $\mathrm{Fe} 2 \mathrm{p}_{3 / 2}$ peak is indicative for minor amounts of $\mathrm{Fe}^{2+}$. The atomic ratio of $\mathrm{Pd} / \mathrm{Fe}$ in the initial state is 0.084 . In comparison, a rough estimation based on free $\mathrm{Pd}$ surface area measured by $\mathrm{CO}$ chemisorption after room temperature reduction and considering the BET surface area of $\mathrm{Pd} / \gamma-\mathrm{Fe}_{2} \mathrm{O}_{3}$ as (111) surface of maghemite yields a ratio of 0.212 , which is in reasonable agreement. In addition, too low $\mathrm{Pd} / \mathrm{Fe}$ ratios from XPS may be caused by geometric effects (e.g. in case of half-spherical Pd particles) and the fact that the information depth is in the range of the average Pd particle size (both in the range of $1 \mathrm{~nm}$ ). The sample was then heated to $523 \mathrm{~K}$ in $25 \mathrm{~Pa}$ of $\mathrm{H}_{2}$ and kept under these conditions for more than $14 \mathrm{~h}$. During this time, the area of the Pd peaks decreased while the area of the Fe 
peaks increased. After $14 \mathrm{~h}$ the $\mathrm{Pd} / \mathrm{Fe}$ ratio is only 0.005 , indicating that more than $90 \%$ of the $\mathrm{Pd}$ disappeared from the surface of the sample, which is in excellent agreement with the $\mathrm{CO}$ chemisorption results, suggesting overgrowth of the Pd particles by iron oxide species as observed by HR-TEM (Fig. 6). Furthermore, the signal for oxidized Pd vanished; only metallic $\mathrm{Pd}$ was detected. In the $\mathrm{Fe} 2 \mathrm{p}$ region, the overall width of the $\mathrm{Fe} 2 \mathrm{p}_{3 / 2}$ signal decreased, which suggests the formation of a more defined surface iron oxide with less different Fe species. This is also reflected by the shift of the position of the shoulder below $710 \mathrm{eV}$ towards higher binding energies. Upon oxidation of the sample at $673 \mathrm{~K}$ in $25 \mathrm{~Pa}$ of $\mathrm{O}_{2}$, the $\mathrm{Pd}$ reappears at the surface. After $5.25 \mathrm{~h}$ more than $25 \%$ of the Pd reappeared, as reflected in the $\mathrm{Pd} / \mathrm{Fe}$ ratio of 0.023 . The $\mathrm{Pd}$ $3 \mathrm{~d}$ region indicates that all $\mathrm{Pd}$ on the surface was oxidized. The low BE shoulder in the Fe $2 \mathrm{p}$ region vanished completely, suggesting the full oxidation of remaining $\mathrm{Fe}^{2+}$ to $\mathrm{Fe}^{3+}$ on the surface under these conditions.

In summary, $\mathrm{CO}$ chemisorption experiments showed a loss of sorption capacity for $\mathrm{CO}$ adsorbed on $\mathrm{Pd}$ after reduction of $\mathrm{PdO} / \gamma-\mathrm{Fe}_{2} \mathrm{O}_{3}$ at elevated temperatures. This loss could be reversed by reoxidation of the sample. Furthermore, after reduction of $\mathrm{PdO} / \gamma-\mathrm{Fe}_{2} \mathrm{O}_{3}$ an amorphous overlayer on Pd particles could be observed by HR-TEM. In situ XPS experiments showed that this overlayer consisted of iron oxide. These results give strong evidence for the existence of SMSI in $\mathrm{Pd} / \mathrm{Fe}_{3} \mathrm{O}_{4}$.

\subsection{Catalytic activity results}

The oxidation of $\mathrm{CO}$ was investigated as catalytic test reaction to characterize $\mathrm{PdO} / \alpha-\mathrm{Fe}_{2} \mathrm{O}_{3}$ and $\mathrm{PdO} / \gamma-\mathrm{Fe}_{2} \mathrm{O}_{3}$, and to probe the effect of SMSI on the catalytic properties. Pd/CNT and $\alpha-\mathrm{Fe}_{2} \mathrm{O}_{3}$ were tested for comparison. CO conversion of $0.065 \%$ at $523 \mathrm{~K}$ was measured on $\alpha-\mathrm{Fe}_{2} \mathrm{O}_{3}$ (after reduction at $573 \mathrm{~K}$ ), with no activity detected below $473 \mathrm{~K}$. Thus, any contribution of the iron oxide support to CO conversion measured on Pd-containing catalysts can be neglected.

The first CO oxidation experiment was carried out under steady-state conditions on initial $\mathrm{PdO} / \alpha-\mathrm{Fe}_{2} \mathrm{O}_{3}$. After temperature-programmed reduction at $523 \mathrm{~K}$ to yield $\mathrm{Pd} / \mathrm{Fe}_{3} \mathrm{O}_{4}$ (cf. Fig. 4), followed by cooling to room temperature in $\mathrm{Ar}$, isothermal $\mathrm{CO}$ oxidation conditions were applied at $373 \mathrm{~K}, 403 \mathrm{~K}, 423 \mathrm{~K}$, and $433 \mathrm{~K}$ for $4 \mathrm{~h}$, respectively, yielding data set a) in the Arrhenius plot shown in Fig. 8. The measurement was repeated after cooling from $433 \mathrm{~K}$ to $373 \mathrm{~K}$, giving data set $b$ ) in Fig. 8. After measuring data set $b$ ), the molar fraction of $\mathrm{CO}$ was kept at $1.0 \%$, but the molar fraction of $\mathrm{O}_{2}$ was changed to $1.0 \%$, then to $2.5 \%$, and back to $1.0 \%$. Under each 
condition, catalytic data were measured for $4 \mathrm{~h}$ at $373 \mathrm{~K}, 403 \mathrm{~K}, 423 \mathrm{~K}$, and $433 \mathrm{~K}$, respectively, repeating the measurement after cooling to $373 \mathrm{~K}$. Finally, the molar fraction of $\mathrm{O}_{2}$ was set again to $0.5 \%$, and data sets c) and d) in Fig. 8 were measured. It can be clearly seen, that the catalyst deactivates drastically in the course of the experiment. The fact that the apparent activation energies $E_{a}$ derived from the Arrhenius plot change from $33 \mathrm{~kJ} / \mathrm{mol}$ for data set a) to $70 \mathrm{~kJ} / \mathrm{mol}$ for data set d) indicates that the deactivation is related to a change of the nature of the active sites with time on stream rather than to simple sintering of Pd particles. Assuming that the SMSI state was formed after the initial reduction, it seems to be destroyed quickly after applying $\mathrm{CO}$ oxidation conditions. Mass transfer calculations were carried out at the highest rate for initial $\mathrm{PdO} / \mathrm{Fe}_{2} \mathrm{O}_{3}$ after reduction at $523 \mathrm{~K}$ to yield $\mathrm{Pd} / \mathrm{Fe}_{3} \mathrm{O}_{4}$ (cf. Fig. 8a). The Weisz-Prater criterion was calculated at $8.5 \cdot 10^{-3}$, indicating negligible internal mass transport limitation (see supplementary information) [44].

To probe and compare the deactivation behavior of different samples, $\mathrm{CO}$ oxidation was carried out in temperature-dependent cycles (Fig. 9). After reductive pre-treatments the samples were heated in the reactive feed to $523 \mathrm{~K}$ with $1 \mathrm{~K} / \mathrm{min}$ and cooled to room temperature, five heating/cooling cycles were conducted. Values of $\mathrm{T}_{50}$, the temperature at $50 \% \mathrm{CO}$ conversion, are given in Table S5. For all iron oxide samples, the main part of deactivation occurred during the first heating cycle. Since after pre-reduction at $523 \mathrm{~K}$ the $\mathrm{T}_{50}$ values for initial $\mathrm{PdO} / \alpha-\mathrm{Fe}_{2} \mathrm{O}_{3}$ (Fig. 9 a) and initial $\mathrm{PdO} / \gamma-\mathrm{Fe}_{2} \mathrm{O}_{3}$ (Fig. 9 c) are nearly identical for all five cycles, both samples are most likely in the same state before the first cycle: $\mathrm{Pd} / \mathrm{Fe}_{3} \mathrm{O}_{4}$, with most of the $\mathrm{Pd}$ surface covered by $\mathrm{FeO}_{\mathrm{x}}$. A comparison of all $\mathrm{T}_{50}$ values measured on iron oxide samples leads to the following conclusion: the SMSI between Pd and iron oxide strongly enhances the catalytic activity of $\mathrm{Pd}$ for $\mathrm{CO}$ oxidation. The $\mathrm{T}_{50}$ values of the first cycle for $\mathrm{PdO} / \alpha-\mathrm{Fe}_{2} \mathrm{O}_{3}$ and $\mathrm{PdO} / \gamma-$ $\mathrm{Fe}_{2} \mathrm{O}_{3}$ after reduction at $523 \mathrm{~K}$, i.e. in the SMSI state, are significantly lower compared to $\mathrm{PdO} / \alpha$ $\mathrm{Fe}_{2} \mathrm{O}_{3}$ after reduction at room temperature, although only a small fraction of the Pd surface area in the SMSI state is accessible and can serve as active sites. The $T_{50}$ values of cycles $2-5$ are the same for all iron oxide containing catalysts. It is interesting to see that even after three cycles, the iron oxide containing catalysts are still subject to deactivation, as indicated by increasing $\mathrm{T}_{50}$ values. Deactivation can either be caused by sintering of Pd particles or by changes in the oxidation state of the iron oxide supports, either at the surface or in the vicinity of Pd particles. STEM shows that Pd particles in the deactivated state after CO oxidation are significantly larger 
compared to Pd particles on a freshly reduced sample (Fig. $3 \mathrm{~b}+\mathrm{d}$ ), suggesting that sintering is one reason for deactivation of the Pd supported iron oxide catalyst. For Pd/CNT sintering should be the main deactivation route (Fig. 9 d). Formation of SMSI or changes in the oxidation state of the support are not expected to play a role because of the non-reducibility of the carbon support. After activation during the first cycle, the performance of $\mathrm{Pd} / \mathrm{CNT}$ was stable during cycles 2-5. Subsequent to the heating/cooling cycles, steady-state measurements under isothermal conditions were carried out. Based on the results of the cycling experiments, an individual temperature range for steady-state measurements was chosen for each catalyst. Within this region, the sample was heated up in steps of $10 \mathrm{~K}$ and then cooled down in steps of $5 \mathrm{~K}$. The data collected during cooling down is shown in Fig. 10 on samples that previously were exposed to the conditions applied in Fig. 9. Additionally, data measured on $\mathrm{PdO} / \alpha-\mathrm{Fe}_{2} \mathrm{O}_{3}$ after reduction at $523 \mathrm{~K}$ without previous temperature cycling (data set a) in Fig. 8), which is representative for the SMSI state, is included for comparison. The iron oxide containing catalysts are more active by an order of magnitude compared to $\mathrm{Pd} / \mathrm{CNT}$. Initial $\mathrm{PdO} / \alpha-\mathrm{Fe}_{2} \mathrm{O}_{3}$ after room temperature reduction, i.e. without SMSI, and $\mathrm{PdO} / \gamma-\mathrm{Fe}_{2} \mathrm{O}_{3}$ after reduction at $523 \mathrm{~K}$, both in the already deactivated states show similar results. The slight differences may be due to different degrees of deactivation that could possibly result in different iron oxide phases present in the support. The data of $\mathrm{PdO} / \alpha-\mathrm{Fe}_{2} \mathrm{O}_{3}$ in the SMSI state after reduction at $523 \mathrm{~K}$ show an increase of activity by an order of magnitude at low temperatures. At higher temperatures the SMSI state decomposes, but still renders the sample twice as active.

In situ XRD experiments were carried out on initial $\mathrm{PdO} / \alpha-\mathrm{Fe}_{2} \mathrm{O}_{3}$ to clarify whether possible bulk changes in the iron oxide support can serve as another reason for the deactivation of the catalyst under $\mathrm{CO}$ oxidation conditions, besides sintering of the particles (cf. Fig. 3 b+d). Fig. S9 indicates that in the initial state, all iron oxide is found to be hematite. After reduction in $5 \% \mathrm{H}_{2}$ at $523 \mathrm{~K}$ the iron oxide is mainly present as magnetite, hematite being a small minority phase. $\mathrm{CO}$ oxidation at $523 \mathrm{~K}$ was then carried out in the XRD cell in two different feeds: 1) CO-rich feed $\left.\left(4.0 \% \mathrm{CO}, 0.5 \% \mathrm{O}_{2}\right), 2\right)$ stoichiometric feed $\left(1 \% \mathrm{CO}, 0.5 \% \mathrm{O}_{2}\right)$. Despite the different oxidation potentials of the respective feeds the diffraction patterns are nearly identical: $\gamma-\mathrm{Fe}_{2} \mathrm{O}_{3}$ (maghemite) was formed in both cases while the minority phase hematite $\left(\alpha-\mathrm{Fe}_{2} \mathrm{O}_{3}\right)$ was still present. Subsequent calcination at $673 \mathrm{~K}$ induced no changes to the maghemite phase, only the content of the hematite phase increased slightly. Increasing the calcination temperature to $1073 \mathrm{~K}$ 
eventually resulted in the formation of $\alpha-\mathrm{Fe}_{2} \mathrm{O}_{3}$. Furthermore, large crystallites of PdO were formed and are visible in the diffraction pattern. The in situ XRD results indicate that bulk changes of the iron oxide, i.e. the oxidation of $\mathrm{Fe}_{3} \mathrm{O}_{4}$ (magnetite) to $\gamma$ - $\mathrm{Fe}_{2} \mathrm{O}_{3}$ (maghemite), occur during $\mathrm{CO}$ oxidation within hours, even in the excess of $\mathrm{CO}$. Hence, these bulk changes may only play a role in the initial deactivation of the catalyst (cf. Fig. 9). The changes of $E_{a}$ shown in Fig. 9 took place over the course of days and are therefore most likely caused by sintering of the Pd particles and the associated loss of active surface area.

In summary, Pd particles supported on iron oxide are much more active for $\mathrm{CO}$ oxidation than $\mathrm{Pd}$ particles supported on CNT, highlighting the widely-studied role of oxide supports for $\mathrm{CO}$ oxidation over metal catalysts. The activity of $\mathrm{Pd}$ on iron oxide can be further increased by partial reduction of the iron oxide. After reduction of the iron oxide at elevated temperatures, when the surface of Pd particles is almost completely covered by Fe species, the activity is increased by an order of magnitude. For samples in this state values of $E_{a}$ as low as $33 \mathrm{~kJ} / \mathrm{mol}$ were found. These findings correlate well with model studies on Fe films grown on $\operatorname{Pt}(111)$, that show highest $\mathrm{CO}$ oxidation activity when $\mathrm{Pt}(111)$ is covered by only a monolayer film of iron oxide (i.e. non-stoichiometric $\mathrm{FeO}_{x}$ ) to form a SMSI-like state, compared to low activities on bare $\mathrm{Pt}(111)$ and on $\mathrm{Pt}(111)$ covered by nm-thick $\mathrm{Fe}_{3} \mathrm{O}_{4}$ films [12, 45]. However, the highly active SMSI state on the powder catalyst studied here is subject to fast deactivation. Deactivation occurs in two ways. The first process is fast and has a strong influence on $E_{a}$, increasing $E_{a}$ to values of $80-90 \mathrm{~kJ} / \mathrm{mol}$. This process may be related to changes in the oxidation state of $\mathrm{Fe}$ species in the vicinity of Pd particles. The second process occurs more slowly and can be explained by sintering of Pd particles.

\section{Conclusions}

Co-precipitation was successfully applied to synthesize the precursor material for Pd catalysts supported on iron oxide. The resulting iron oxide can either be hematite, magnetite or maghemite depending on the subsequent processing of the precursor material. In all cases, well defined catalysts with high specific surface areas and high dispersion of Pd were obtained.

The existence of SMSI between $\mathrm{Pd}$ and iron oxide was strongly evidenced on $\mathrm{Pd} / \mathrm{Fe}_{3} \mathrm{O}_{4}$ by a combination of $\mathrm{CO}$ chemisorption experiments, electron microscopy, and in situ XPS experiments. Upon reduction at elevated temperatures, the $\mathrm{CO}$ chemisorption capacity of $\mathrm{Pd}$ is strongly decreased, oxidation can reverse the effect. HR-TEM micrographs revealed the presence 
of an overlayer on Pd particles after reduction at elevated temperatures. Finally, in situ XPS experiments confirmed that the overlayer consists of Fe species, and that the process of encapsulation of $\mathrm{Pd}$ particles is reversible.

SMSI has a strong effect on the catalytic properties of Pd particles. The activity for CO oxidation is strongly enhanced when the Pd particles are covered by Fe species. However, this state is not stable under the applied reaction conditions. Catalyst deactivation occurred in two ways. A fast process has direct influence on the nature of the active site and may be correlated to changes in the oxidation state of Fe species. A second process is sintering of the Pd particles with time on stream. After deactivation, Pd supported on iron oxide is still an order of magnitude more active than Pd supported on a non-reducible support like carbon nanotubes.

We have shown that the SMSI state is easily decomposed in the presence of oxidizing atmospheres, however this highly active state may be stable under highly reducing atmosphere (e.g. in excess $\mathrm{H}_{2}$ ). Therefore, the use of $\mathrm{Pd}$ /iron oxide as a catalyst for the preferential oxidation of $\mathrm{CO}$ in presence of hydrogen - a reaction critical to $\mathrm{H}_{2}$ purification for fuel cell applications, may be feasible. 


\section{Acknowledgements}

The Helmholtz Zentrum Berlin is acknowledged for providing beamtime at BESSY II (ISISS beamline) and ongoing support. 


\section{References}

[1] S. J. Tauster, S. C. Fung, R. L. Garten, J. Am. Chem. Soc. 100 (1978) 170.

[2] S. J. Tauster, S. C. Fung, R. T. K. Baker, J. A. Horsley, Science 211 (1981) 1121.

[3] R. T. K. Baker, E. B. Prestridge, R. L. Garten, J. Catal. 56 (1979) 390.

[4] J. Santos, J. Phillips, J. A. Dumesic, J. Catal. 81 (1983) 147.

[5] D. J. Dwyer, J. L. Robbins, S. D. Cameron, N. Dudash, J. Hardenberg, in: R. T. K. Baker, S. J. Tauster, J. A. Dumesic (Eds.), Strong Metal-Support Interactions, ACS Symposium Series, Washington, 1986, p. 21.

[6] Y. W. Chung, Y. B. Chao, in: R. T. K. Baker, S. J. Tauster, J. A. Dumesic (Eds.), Strong Metal-Support Interactions, ACS Symposium Series, Washington, 1986, p. 54.

[7] E. J. Braunschweig, A. D. Logan, A. K. Datye, D. J. Smith, J. Catal. 118 (1989) 227.

[8] A. K. Datye, D. S. Kalakkad, M. H. Yao, D. J. Smith, J. Catal. 155 (1995) 148.

[9] T. Uchijima, Cat. Today 28 (1996) 105.

[10] Z.-H. Qin, M. Lewandowski, Y.-N. Sun, S. Shaikhutdinov, H.-J. Freund, J. Phys. Chem. C $112(2008) 10209$.

[11] Z.-H. Qin, M. Lewandowski, Y.-N. Sun, S. Shaikhutdinov, H.-J. Freund, J. Phys.: Condens. Matter 21 (2009), 134019.

[12] Y.-N. Sun, Z.-H. Qin, M. Lewandowski, E. Carrasco, M. Sterrer, S. Shaikhutdinov, H.-J. Freund, J. Catal. 266 (2009) 359.

[13] Y.-N. Sun, L. Giordano, J. Goniakowski, M. Lewandowski, Z.-H. Qin, C. Noguera, S. Shaikhutdinov, G. Pacchioni, H.-J. Freund, Angew. Chem. Int. Ed. 26 (2010) 4418.

[14] Y. Martynova, B. H. Liu, M. E. McBriarty, I. M. N. Groot, M. J. Bedzyk, S. Shaikhutdinov, H. J. Freund, J. Catal. 301 (2013) 227.

[15] Y. Martynova, M. Soldemo, J. Weissenrieder, S. Sachert, S. Polzin, W. Widdra, S. Shaikhutdinov, H.-J. Freund, Catal. Lett. 143 (2013) 1108.

[16] R. Meyer, M. Bäumer, S. K. Shaikhutdinov, H.-J. Freund, Surf. Sci. 546 (2003) L813.

[17] H.-J. Freund, G. Meijer, M. Scheffler, R. Schlögl, M. Wolf, Angew. Chem. Int. Ed. 50 (2011) 10064.

[18] A. Satsuma, K. Osaki, M. Yanagihara, J. Ohyama, K. Shimizu, Appl. Catal. B 132-133 (2013) 511.

[19] M. M. Gadgil, S. K. Kulshreshtha, J. Mol. Catal. A: Chem. 95 (1995) 211.

[20] A. V. Kalinkin, V. I. Savchenko, A. V. Pashis, Catal. Lett. 59 (1999) 115.

[21] S. Golunski, R. Rajaram, N. Hodge, G. J. Hutchings, C. J. Kiely, Catal. Today 72 (2002) 107.

[22] R. Meyer, Sh. K. Shaikhutdinov, H.-J. Freund, Z. Phys. Chem. 218 (2004) 905.

[23] B. Qiao, L. Liu, J. Zhang, Y. Deng, J. Catal. 261 (2009) 241.

[24] X. C. Jiang, A. B. Yu, J. Mater. Process. Technol. 209 (2009) 4558.

[25] L. Liu, F. Zhou, L. Wang, X. Qi, F. Shi, Y. Deng, J. Catal. 274 (2010) 1.

[26] S. Chen, R. Si, E. Taylor, J. Janzen, J. Chen, J. Phys. Chem. C 116 (2012) 12969.

[27] T. Engel, G. Ertl, J. Chem. Phys. 69 (1978) 1267.

[28] T. Engel, G. Ertl, in: D. A. King, J. P. Woodruff (Eds.), The Chemical Physics of Solid Surfaces and Heterogeneous Catalysis, Vol. 4, Elsevier, Amsterdam, 1982, p. 73.

[29] S. M. McClure, D. W. Goodman, Chem. Phys. Lett. 469 (2009) 1.

[30] J. Liu, B. Sun, J. Hu, Y. Pei, H. Li, M. Qiao, J. Catal. 274 (2010) 287.

[31] H. Hildebrand, K. Mackenzie, F. G. Kopinke, Appl. Catal. B 91 (2009) 389.

[32] W. Sun, Q. Li, S. Gao, J. K. Shang, Appl. Catal. B 125 (2012) 1-9. 
[33] D. Balzar, in: R. L. Snyder, H. J. Bunge, and J. Fiala (Eds.), Defect and Microstructure Analysis by Diffraction, Oxford University Press, Oxford, 1999, p. 94.

[34] K. S. W. Sing, D. H. Everett, R. A. W. Haul, L. Moscou, R. A. Pierotti, J. Rouquérol, T. Siemieniewska, Pure Appl. Chem. 57 (1985) 603.

[35] A. Knop-Gericke, E. Kleimenov, M. Hävecker, R. Blume, D. Teschner, S. Zafeiratos, R. Schlögl, V. I. Bukhtiyarov, V. V. Kaichev, I. P. Prosvirin, A. I. Nizovskii, H. Bluhm, A. Barinov, P. Dudin, M. Kiskinova, Adv. Catal. 52 (2009) 213.

[36] NIST Electron Inelastic-Mean-Free-Path Database, Version 1.2, 2010.

[37] S. Tanuma, C. J. Powell, D. R. Penn, Surf. Interface Anal. 17 (1991) 911.

[38] J. J. Yeh, I. Lindau, At. Data Nucl. Data Tables 32 (1985) 1.

[39] T. Fujii, F. M. F. de Groot, G. A. Sawatzky, F. C. Voogt, T. Hibma, K. Okada, Phys. Rev. B 59 (1999) 3195.

[40] C. R. Brundle, T. J. Chuang, K. Wandelt, Surf. Sci. 68 (1977) 459.

[41] G. W. van Oosterhout, C. J. M. Rooijmans, Nature 181 (1958) 44.

[42] A. N. Shmakov, G. N. Kryukova, S. V. Tsybulya, A. L. Chuvilin, L. P. Solovyeva, J. Appl. Cryst. 28 (1995) 141.

[43] M. Brun, A. Berthet, J. C. Bertolini, J. Electron Spectrosc. Relat. Phenom. 104 (1999) 55.

[44] P. B. Weisz, C. D. Prater, Adv. Catal. 6 (1954) 143.

[45] M. Willinger et al., Angew. Chem. (2014) accepted. 


\section{Figure legend}

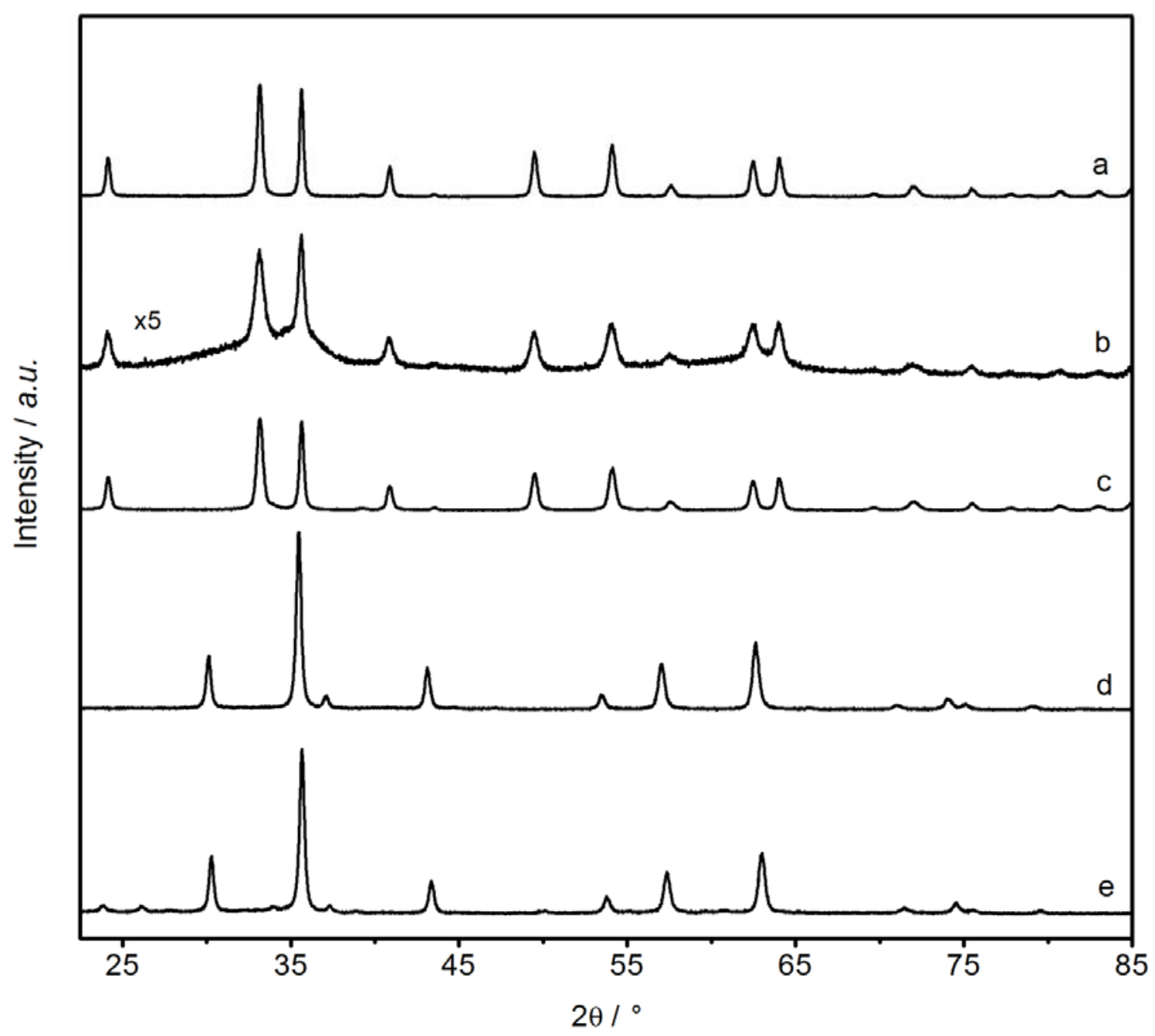

Fig. 1: XRD patterns of (a) the Pd-free precursor calcined at $823 \mathrm{~K}$, (b) the Pd-containing precursor calcined at $673 \mathrm{~K}$, (c) the Pd-containing precursor calcined at $823 \mathrm{~K}$, (d) sample (c) reduced at $523 \mathrm{~K}$, (e) sample (d) calcined at $673 \mathrm{~K}$. 

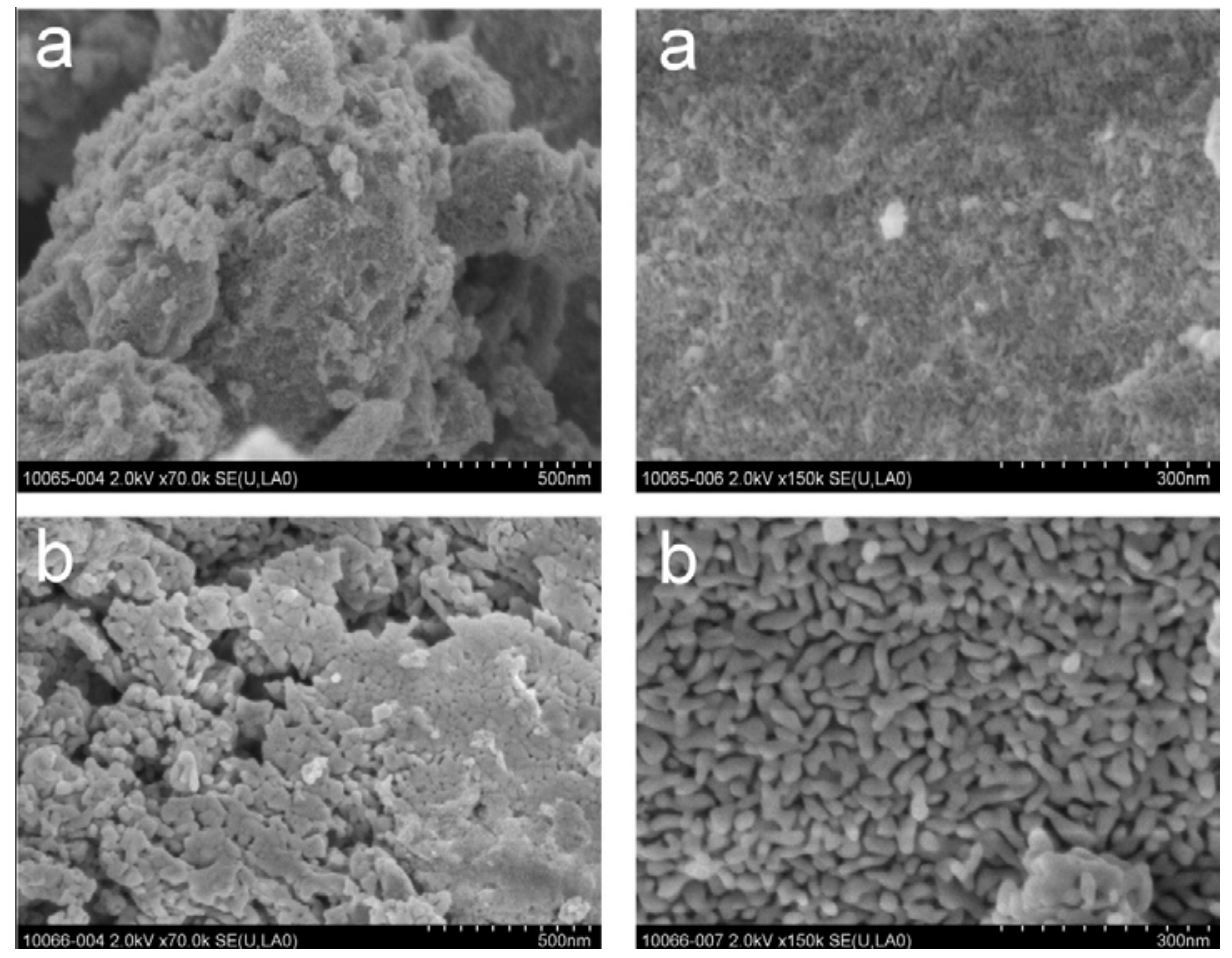

Fig. 2: SEM micrographs of the initial Pd-containing precursor (a) after calcination at $673 \mathrm{~K}$ and (b) after calcination at $823 \mathrm{~K}$. 

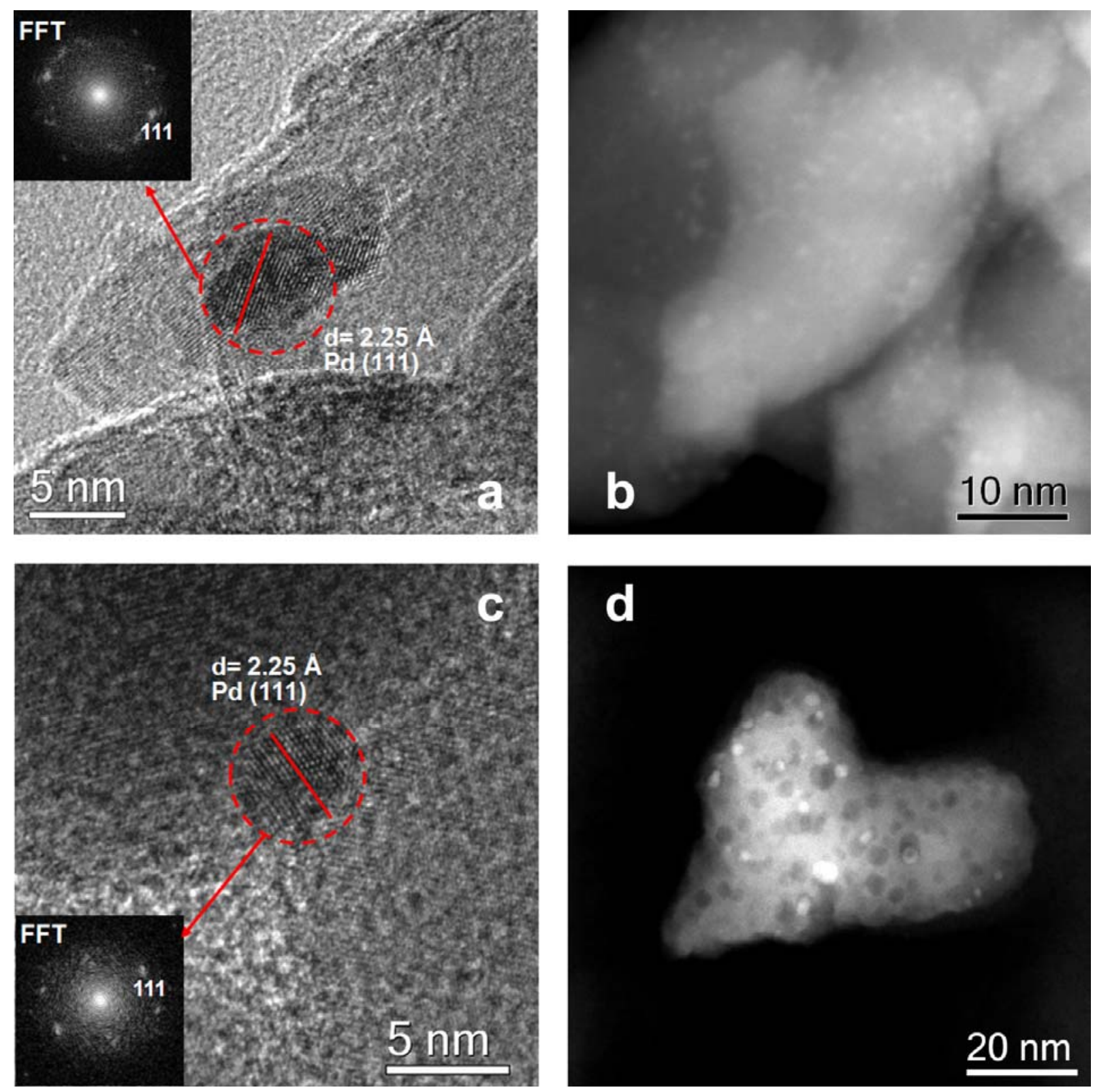

Fig. 3: HR-TEM (left) and HAADF STEM (right) micrographs of initial $\mathrm{PdO} / \alpha-\mathrm{Fe}_{2} \mathrm{O}_{3}$ after reduction at $523 \mathrm{~K}(\mathrm{a}, \mathrm{b})$ and after $\mathrm{CO}$ oxidation (c, d). 


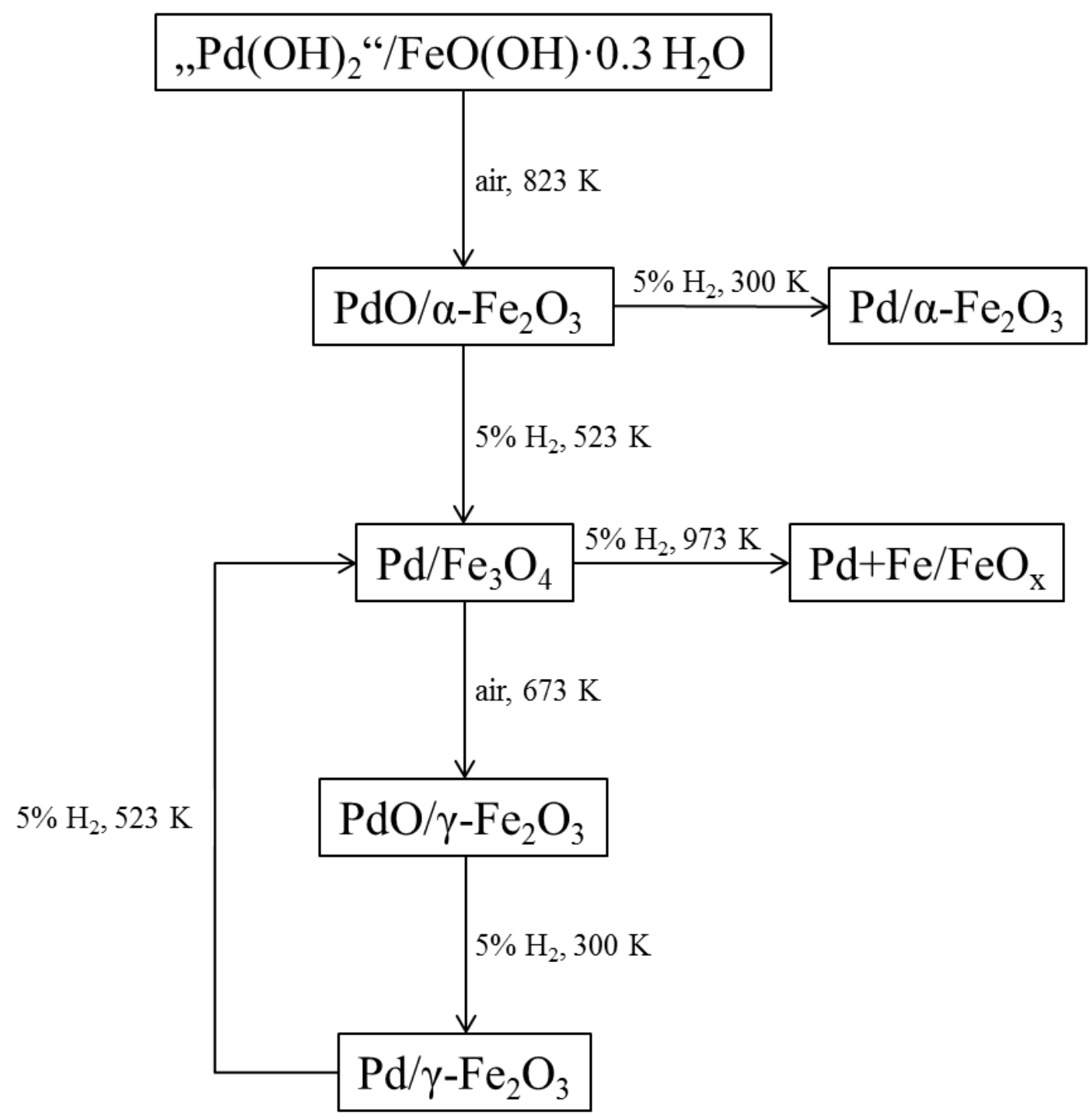

Fig. 4: Phase evolution of the Pd-containing iron oxide supports derived from thermal analysis and XRD results. 


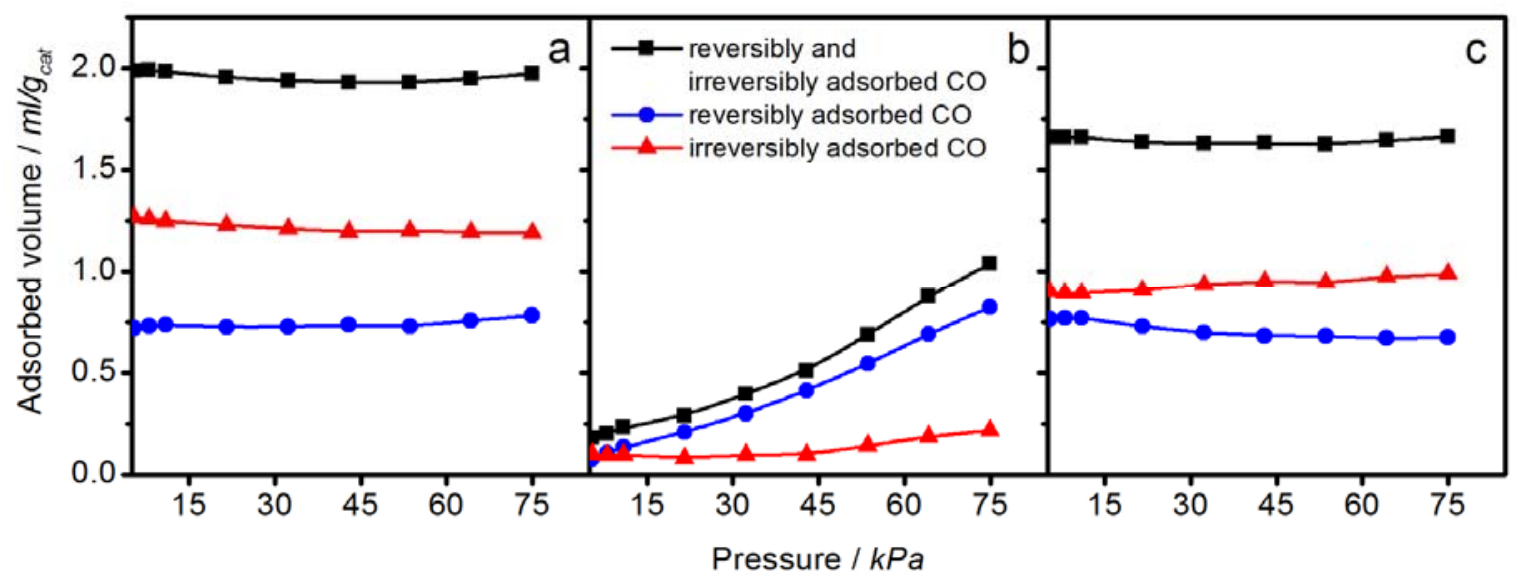

Fig. 5: Results of $\mathrm{CO}$ chemisorption experiments: adsorption isotherms of $\mathrm{CO}$ on $\mathrm{PdO} / \gamma-\mathrm{Fe}_{2} \mathrm{O}_{3}$ (a) after reduction at room temperature, (b) after reduction at $523 \mathrm{~K}$, and (c) after re-oxidation of (b) at $673 \mathrm{~K}$ followed by reduction at room temperature.
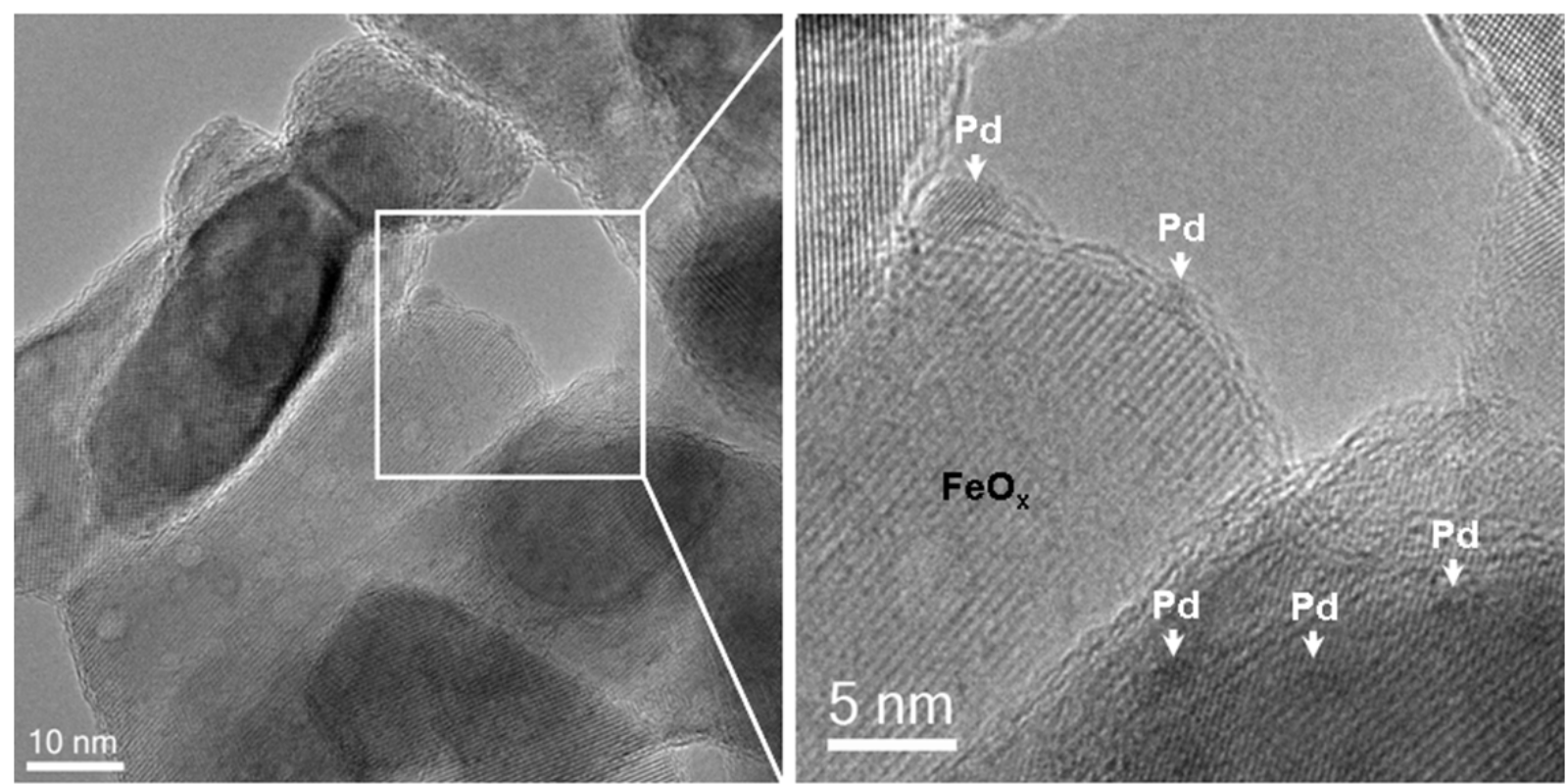

Fig. 6: HR-TEM image of initial $\mathrm{PdO} / \gamma-\mathrm{Fe}_{2} \mathrm{O}_{3}$ after reduction at $523 \mathrm{~K}$ to form the SMSI state. In on-edge views of larger Pd particles an amorphous overlayer covering the particles can be seen. 

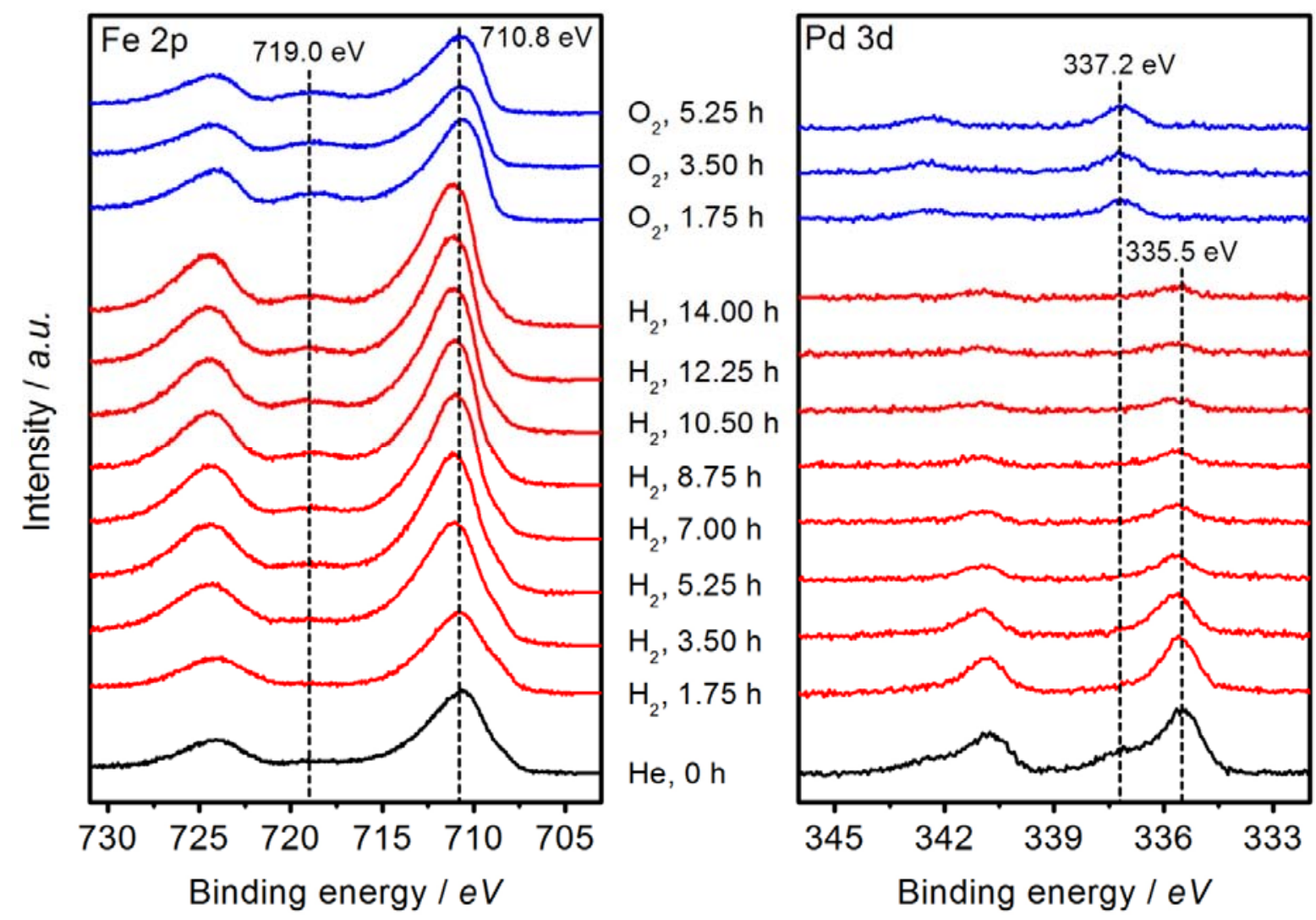

Fig. 7: Results of in situ XPS experiments: Fe 2p and Pd 3d core level regions after different treatments of $\mathrm{PdO} / \gamma-\mathrm{Fe}_{2} \mathrm{O}_{3}$. The initial state was investigated in $25 \mathrm{~Pa}$ of $\mathrm{He}$ at $423 \mathrm{~K}$ (bottom spectrum). Subsequently, the reduction process was investigated in $25 \mathrm{~Pa}$ of $\mathrm{H}_{2}$ at $523 \mathrm{~K}$ over a period of $14 \mathrm{~h}$. Finally, the re-oxidation process was investigated in $25 \mathrm{~Pa}$ of $\mathrm{O}_{2}$ at $673 \mathrm{~K}$ over a period of $5.25 \mathrm{~h}$. Data has been background corrected (Shirley-type) and offset for clarity. 


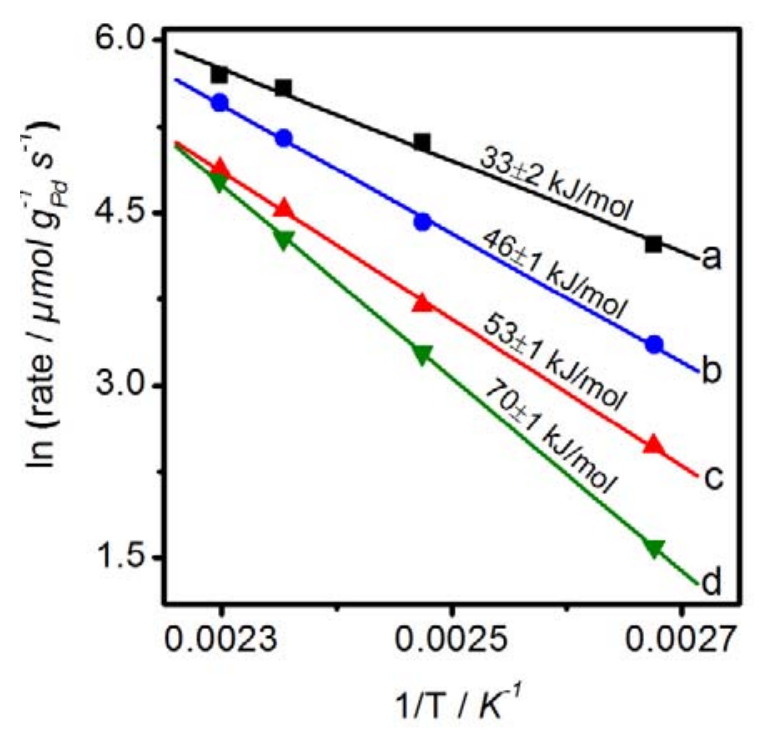

Fig. 8: Arrhenius plot of catalytic data and apparent activation energies measured on initial $\mathrm{PdO} / \alpha-\mathrm{Fe}_{2} \mathrm{O}_{3}($ mass $=26.7 \mathrm{mg})$ : a) after reduction at $523 \mathrm{~K}, \mathrm{~b}$ ) after measuring data a), c) after several experiments at higher $\mathrm{O}_{2} / \mathrm{CO}$ ratios, d) after measuring data $\mathrm{c}$ ). The given error of apparent activation energies is based on the uncertainty of the linear fitting. The actual error may be higher. 


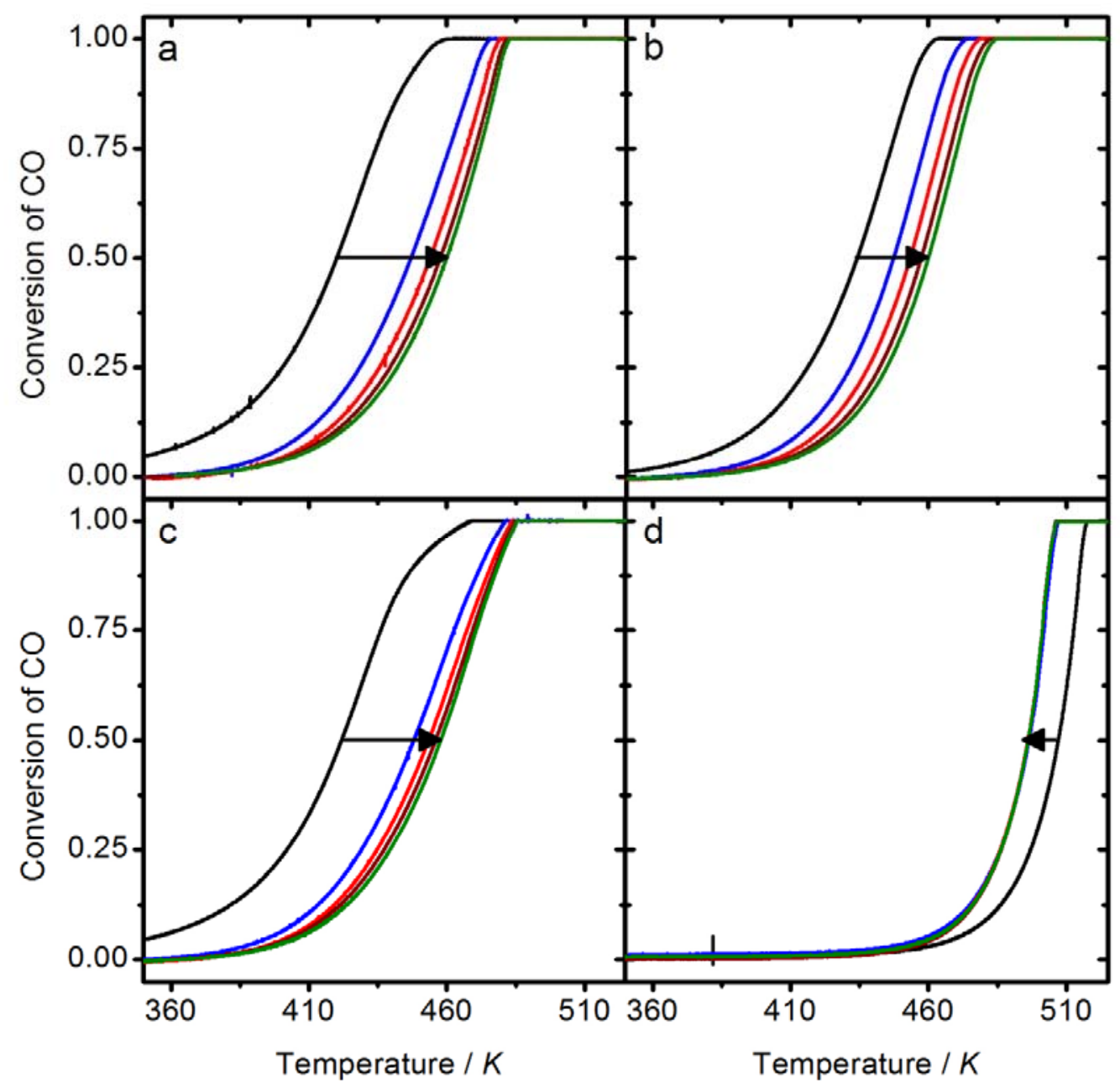

Fig. 9: Temperature-programmed $\mathrm{CO}$ oxidation by repeated heating/cooling cycles with $1 \mathrm{~K} / \mathrm{min}$ in a flow of $1.0 \% \mathrm{CO}$ and $0.5 \% \mathrm{O}_{2}$ in Argon (total flow $100 \mathrm{ml} / \mathrm{min}$ ): a) $\mathrm{PdO} / \alpha-\mathrm{Fe}_{2} \mathrm{O}_{3}$ after reduction at $523 \mathrm{~K}$, b) $\mathrm{PdO} / \alpha-\mathrm{Fe}_{2} \mathrm{O}_{3}$ after reduction at room temperature, c) $\mathrm{PdO} / \gamma-\mathrm{Fe}_{2} \mathrm{O}_{3}$ after reduction at $523 \mathrm{~K}$; d: $\mathrm{PdO} / \mathrm{CNT}$ after reduction at $523 \mathrm{~K}$. The direction of the arrow marks the chronological sequence of cycles 1-5. In d) cycles 2-5 are on top of each other. 

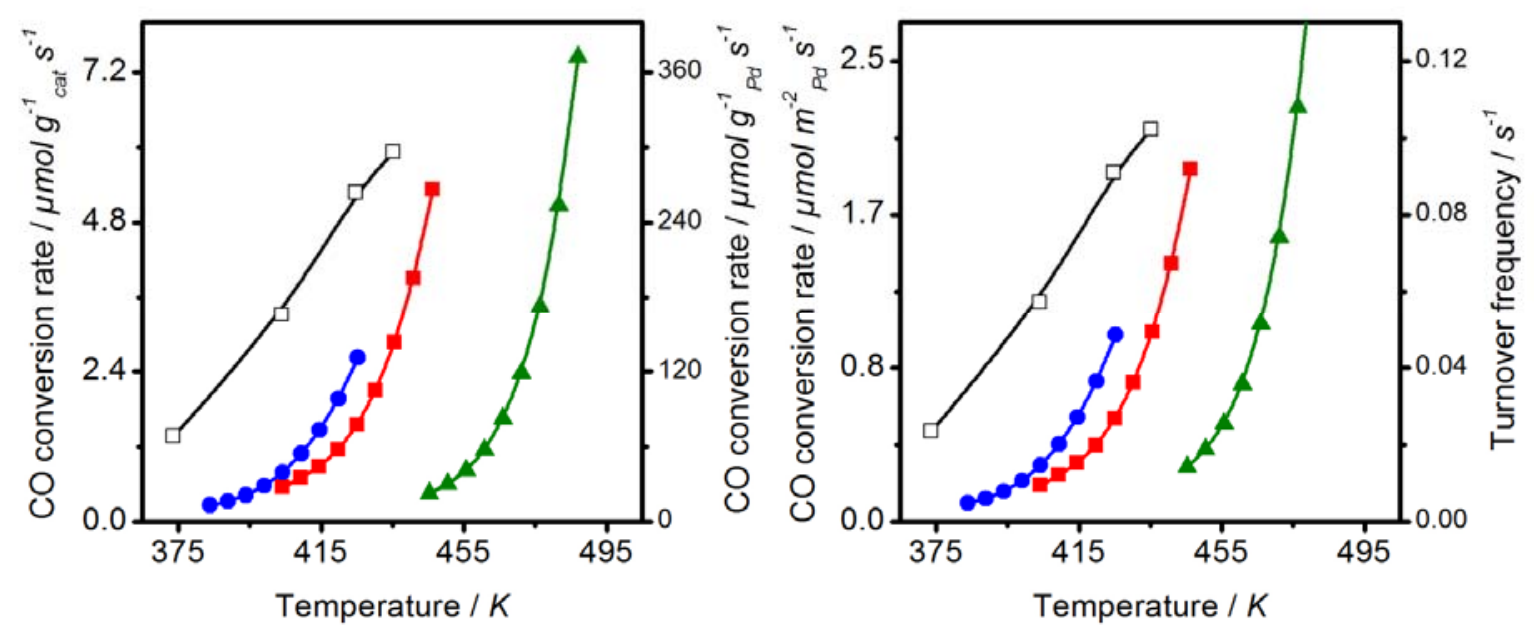

Fig. 10: Steady-state CO conversion rates measured after deactivation tests (cf. Fig. 9); filled squares: initial $\mathrm{PdO} / \alpha-\mathrm{Fe}_{2} \mathrm{O}_{3}$ after reduction at room temperature; circles: initial $\mathrm{PdO} / \gamma-\mathrm{Fe}_{2} \mathrm{O}_{3}$ after reduction at $523 \mathrm{~K}$; triangles: initial $\mathrm{PdO} / \mathrm{CNT}$ after reduction at $523 \mathrm{~K}$. Rates are normalized to sample mass, to Pd mass (assuming a Pd content of $2.0 \mathrm{wt} \%$ for all samples), to specific Pd surface area derived from CO chemisorption experiments, and to the number of $\mathrm{Pd}$ surface atoms (turnover frequency), assuming that every Pd surface atom represents an active site. Data measured with $\mathrm{PdO} / \alpha-\mathrm{Fe}_{2} \mathrm{O}_{3}$ in the SMSI state, directly after reduction at $523 \mathrm{~K}$ without deactivation test, is included for comparison (hollow squares). 